and formed more numerous convolutions and fissures in consequence, but the pharynx may not be changed from the original inclination.

5. The softer brain is likely to undergo more rapid changes than the harder skull, either in the evolution of species or the individual, and the mere cranial conformation may or may not, therefore, be an index to brain area and intelligence, and whatever changes may occur in the skull due to brain increase have reference more to enabling the brain to find room in the cranium, so that a higher forehead may render the more erect basi-occipital unnecessary, or vice versa, and normal or abnormal growth of brain may raise both osseous portions.

Some mongrel dogs may inherit a larger brain from one parent and smaller brain-case from another, which would account for the deep indentations in their skulls, the pressure causing them sometimes to suffer from epilepsy and other brain derangements; this disparity is not likely to be so great in the offspring of bettermated species.

6. Many other matters could be considered, such as centres of ossification and cartilaginous persistence between such parts as the basilar process and sphenoid, enabling adjustment of the pharynx to the changed medulla angle.

70 State Street, Chicago.

\section{INDICATIONS OF A RAINY PERIOD IN SOUTHERN PERU.}

$$
\text { BY A. E. DOUGLASs. }{ }^{1}
$$

IT is sufficiently easy to assert that at some remote period this country had abundance of water; but very few writers have taken the trouble to point out the actual indications to that effect.

There are two causes which operate to make this climate dry. The first is found in the south-east trade-winds being stopped by the high mountain ranges in the interior to the east of us. The second consists in the fact that the winds which do reach our sea-coast come from the colder regions to the south, and consequently will take up moisture and not deposit it. Therefore, a change from a wet to a dry climate was probably caused by a considerable increase in the average elevation of the Andes. If such was the case it must have occurred at some very remote period.

Before entering fully upon the subject, it is safe to remind one's self that a small amount of water acting through a great length of time can accomplish almost as much wearing as a great amount in a short time. Therefore, the numerous large and deep ravines in this region do not necessarily indicate a great quantity of water at some past epoch.

The purpose of this paper, then, is to point out some particulars which indicate that at some geological epoch there was abundance of water in this region. Unmistakable evidence has been found in two places: on Charchani and on the Pampa of La Joya.

A trip to the observatory meteorological station on Charchani, at an altitude of 16,650 feet, reveals many interesting facts. The green valley of Arequipa seems to be alluvial flats of river and perhaps lake deposits; the pink-colored pampa of Uchumayo is evidently the original volcanic tufa; while the dark-brown pampa, stretching out some ten miles from the mountain and containing a very thin vegetation, is an enormous "wash" from the mountain itself. In this is shown a water action on a scale surpassing anything that can be found about the city itself. If Charchani is a remnant of an ancient crater-ring, as seems not improbable, then a portion half as large as the present mountain has been washed down into the valley.

But there is a still more noticeable feature on the mountain itself. At an altitude of about 14,500 feet, on the ridge west of the great central ravine, the road passes for perhaps half a mile through an area of bowlders worn by water action into all sorts of curious and fantastic shapes. The rest of the ridge to its top is a regular glacial moraine of gravel and bowlders. On leaving this

${ }^{1}$ First assistant at the Boydun station of the Harvard College Observatory, Arequipa, Peru. ridge and reaching the final slope to the summit, a little below snow-line, one finds every ledge of rock smoothed and polished on the surface, with long shallow scratches pointing down the mountain - proofs of glacial action. These striated ledges are especially noticeable at and just below the meteorological station. Therefore, at some period this pocket where our station is, between the main summit and the broken ridges to the east, was filled with ice to a depth of a thousand feet or more. This glacier slowly moved downward, completely filling the valley and at some point separating into two streams, one of which filled the great central ravine down to the spring, Canchero, and the other turned more to the west, going down probably to the same altitude of 13,200 feet.

Now the significance of an enormous glacier on Charchani is this: ravines and river valleys can be made by a small amount of water acting through a long period, but glaciers cannot; the water, or snow, must be all there at once. Moreover, the greater the supply of snow for a glacier the farther down the mountain it will come. Now, the temperature of this spring at noon of April 12 , this year, was $45.5^{\circ} \mathrm{F}$., and it will be shown later that the land had a less elevation in the rainy period than at present. The climate could not, therefore, have been colder. As this glacier came down to an altitude where the mean annual temperature was considerably above freezing, as shown by the present temperature of the spring, the snow supply must have been not merely moderate but quite abundant.

If we had rain enough at the present day to make these dry pampas the gardens they might be, this glacier would be seen on Charchani.

The evidence to be found on the Pampa of La Joya is equally conclusive but not equally striking. Not far below Vitor is a large ridge of volcanic mud to the west of the track. This ridge runs about north-east and south-west, and is bounded along its south east side by an open cliff where the bank has been caved away by a river flowing against it. Stretching away from this hank is the old river-bed, very broad and shallow. At a higher level, to the east of the track, the river-bed contracts into a narrow and deep channel. A surface river on the Pampa of La Joya would necessitate vastly more abundant rains than at the present day. There must have been a supply greatly in excess of the loss by evaporation or sinkage into the earth.

There are other facts also which bear on this question. Lake Titicaca once covered many times its present area. Innumerable shell-fish lived in its waters, whose remains are now found as fossils at Chililaya, Huancané, and other places, many feet above the present lake-level. The signs of this increased size are still so evident and the fossils are so much like the living species of shell-fish, that, geologically speaking, the rainy period which caused this increase and at a lower altitude supported a tropical vegetation was recent; historically, of course, its antiquity was immense. The palaces and houses on the island of Titicaca were built with the lake at practically its present level, and Tiahuanaco is not more than $\mathbf{1 5 0}$ feet above it. Coal deposits are found on the island of Titicaca and at Sumbay, but the tropical vegetation which formed them must be placed in a past so remote that the enlargement of Lake Titicaca and the glaciers on Charchani are but as yesterday.

In the beginning of this article I referred to the fact that an increase in the elevation of the mountains to the east of us may have caused the elimate to become dry. That such an increase has occurred in recent geological times can scarcely be doubted. From above Tambo station down to the present sea-level traces of surf-action may be found. That means that the coast has been gradually rising out of the sea to the extent of 1,100 feet in recent geologic times. Whether it did it with perfect regularity, by occasional periods of rapid rising, or by sudden elevations, a thorough examination of the region would show. At Mollendo it is evident that the coast has not risen more than two or three feet in the last hundred years, if it has risen at all, and the fact that guano has been accumulating on the islands along the coast for many thousand years indicates that for a long period the coast has been practically stationary. Nevertheless, there can be no doubt that the last change in the coast-level was a rise of 1,100 
feet. That, to be sure, was not very much, but it must have materially altered the relative lengths of the wet and dry seasons.

Thus we have direct evidence to the following effect: For many thousand years, going back far beyond the recognized period of human habitation, the climate has been very much as it is at present. That was preceded by a slow rise of the land out of the sea, which caused the climate to change from wet to dry. But under the wet climate the elevation of the land was still too great, and perhaps the duration of the epoch was too short, to produce a luxuriant tropical vegetation; otherwise there would be to-day extensive coal-fields. However, the wet climate was sufficient to greatly alter the face of the country. Lake Titicaca was of enormous area, fed perhaps by the melting glaciers. In the almost continuous rainy season, huge turbid rivers roared and tumbled down these western slopes of the Cordillera, while on each mountain summit vast quantities of snow fell, only to pursue its way down the steep slopes, carving out valleys, building up ridges, and by its melting wearing out deep ravines, which grow smaller as they become lost in the broad level plain below. Under such luxuriance of moisture the valley of Arequipa must have teemed with animal and vegetable life, the barren hills to the south were clothed in green, and the desert of La Joya blossomed like a garden.

\section{CURRENT NOTES ON ANTHROPOLOGY.-XVII.}

[Edited by D. G. Brinton, M.D., LL.D.]

The Ancient Vans.

THE people who in proto-historic time lived at the foot of Mount Ararat, on the plains around Lake Van, and about the head-waters of the Araxes, were known to Herodotus as the Alarodi, which is a Greek form of the Assyrian Urartu, of which Ararat is the Hebrew form. They seem to have called themselves Chaldeans, Chaldi, but their language was neither Semitic nor Aryan. They learned to write it in cuneiform characters, and a considerable number of their inscriptions have been recovered, dating $750-850$ B.C., about.

In a late number of the Zeitschrift für Ethnologie is a valuable contribution to our knowledge of these inscriptions by Messrs. Belck and Lehmann. The former traversed some five thousand kilometers of Russian and Turkish Armenia last year, and carefully copied quite a number of hitherto unknown Vannic inscriptions; to the decipherment of which Dr. Lehmann devoted himself with much success. They date from half a dozen different reigns previous to the destruction of the Vannic kingdom by Tiglathpileser in 742 B.C.

The most interesting, the longest, and the most difficult to decipher, on account of the new words and ideograms it contains, is one from the stele of Rusas. It apparently was set up to celebrate the completion of some important works in irrigation and laying-out of gardens and orchards.

The inscriptions are carefully reproduced in autotype, and offer new and valuable materials for students of this little-known tongue.

\section{Laws of Human Evolution.}

The most valuable summary of the facts and laws of human evolution that $I$ have seen for a long time is contained in the Cartwright Lectures for 1892, delivered by Prof essor Henry F. Osborn of Columbia College, New York. These admirably clear and able addresses, three in number, discuss the many knotty questions involved in this topic with temperate judgment and a complete mastership of the facts.

Many of his conclusions are of the utmost importance to the practical anthropologist, and to the majority will have a novel force; for instance, that man is anatomically quite degenerate, only his hand and his brain comparing favorably with mammalian anatomy generally. He is now in a state of very rapid evolution, or rather transformation, for, according to our author's figures, more than thirty of his organs are degenerating to twenty which are developing. This action is especially active in certain centres, of which eight are mentioned; but in them the rate of change is by no means uniform. The most conspicuous variations are reversions, and in the matter of advance, the evidence is abundant that structure lags far behind function.

In the muscular system the evolution of a new type consists in the accumulation of anomalies in a certain direction by heredity. There are on the average nine anomalies of the muscles in each individual. How these come about is variously explained. The French theory that all anomalies reproduce earlier normal structures, seems too absolute. Here comes in the puzzling question as to what is the active force in producing variations, and preserving those which are valuable to the species. After a careful review of the evidence, the lecturer reaches the conclusion that the theory of use and disuse, along with the hereditary transmission of acquired variations, encounters less difficulties than that of the accumulation of fortuitous favorable variations by natural selection.

Of course. the theories of Weissmann, that acquired traits do not become hereditary, have to be considered, and are not found to be sufficiently established.

\section{Suggestions for a Universal Language.}

The evolution of linguistics is in two opposed directions; on the one hand, there are societies and patriotic guilds constantly cultivating and preserving dialects and isolated languages, printing papers in them, and trying to make the rest of the world learn them; and, on the other, there is a growing party demanding that some one or a very few tongues be adopted for the general commercial, social, and scientific business of the world. The latter class is again divided into those who would select one or two of the already existing languages, and their opponents, who think a new and simple tongue had better be manufactured for the purpose. Of the latter the Internationale Weltsprache Gesellschaft of Vienna is among the most active: It has just issued a "Grammatik der Weltsprache" (Mondolingue), which is but one of its many publications in favor of the tongue devised by Dr. Julius Lott, from whom (Wien, II. 2. Schüttelstrasse 3) these publications may be had.

Professor A. MacFarlane of Austin, Texas, has also a valuable paper in the Texas Academy of Science Transactions, on " Exact Analysis as the Basis of Language." He reaches the conclusion that a natural language is hetter suited to scientific development than one which is artificial. Another recent writer on the same subject is M. Raoul de la Grasserie of Rennes, France.

\section{Languages of the Gran Chaco.}

The extensive district in northern Buenos Ayres called El Gran Chaco, "The Great Hunting-Ground," has been linguistically almost a terra incognita. Inhabited by numerous roving tribes of uncertain affinities, up to the present time we have had of its numerous dialects only one published grammar, and for it no corresponding people could be found, none who speak the tongue which it sets forth!

This want bas now been happily filled by two publications which have been issued by the Museo de la Plata; the one, a work composed in 1856 by the Rev. Francisco Tavolini, entitled " Reglas para aprender à hablar la Lengua Moscovita;" the other, by Samuel A. Lafone Quevedo, " Principios de Gramatica Mocovi." Both refer to the same dialect, better known as the Mbocobi. It is closely allied to the Abipone and Toba, and is a member of the stock which, in my "American Race," I have designated by the Tupi term, "Guaycuru."

The two works are in a measure supplementary, Mr. Lafone Quevedo having made use of previous writers, principally Barcena, Dobrizhoffer, and Tavolini, to form his analysis of the tongue. $\mathrm{He}$ is also the editor of Tavolini, and holds out the promise of other grammars of the Argentine languages, from unpublished sources. We who interest ourselves in such studies, shall look forward with interest to this series, and hope that the financial storms of the Argentine Republic will not delay its appearance. 